\title{
THE ROLE OF ARTIFICIAL SEEDING
}

\author{
By JOHN REVEL'
}

SCOPE

1. In 1957, the Surveys Division of the B.C. Forest Service estimated that there were 12 million acres of forest land occupied by Non-Commercial Cover (N.C.C.), and 6.4 million acres which were Not Satisfactorily Restocked (N.S.R.) in British Columbia. Approximately 2 million acres of the N.S.R. were classified as plantable and not expected to restock naturally (1).

2. In the ten-year period, 1952 to 1961 , an average of 460,000 acres was burned annually in British Columbia by unintentional fires (2).

3. In 1961, 72,000 acres were logged in the Vancouver Forest District (2).

4. On the basis of the above figures, in excess of 500,000 acres of forest land are logged or burned annually in B.C.

5. A large proportion of this acreage will restock naturally, especially that acreage which results from small forest fires.

6. Burning or mechanical site preparation, when associated with a seed source, and when timed with a seed crop, will facilitate natural regeneration.

7. Assuming full utilization of natural seeding, a conservative estimate is that more than 100,000 acres should be planted or seeded annually in B.C., if denuded lands are to be promptly restocked. This estimate does not include the reforestation of N.S.R. and N.C.C. forest land outlined in 1957 (1).

8. Faced with such a vast acreage of forest land in need of reforestation, the most important improvement in reforestation, from an extensive viewpoint, is to satisfactorily restock a maximum acreage of N.S.R. annually, and to use the supply of seed, planting stock, and labour efficiently to this end.

Planting, based on present concepts, is superior to artificial seeding in most aspects. Planting can shorten the period required to grow trees to merchantable size. It provides better control of stocking and distribution, faster initial growth of seedlings, and is a low risk venture when compared to seeding. Planting of 2-year-old seedlings by-passes the high-risk period of germination and establishment of germinates. When seeding is used there is a risk of over-stocking which might require an early, non-commercial thinning.

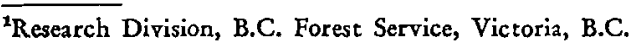


From this viewpoint, and disregarding relative costs for the moment, the theoretical answer would be to increase the production of planting stock so that all N.S.R. requiring reforestation could be planted. The problem of significance however is not specifically a shortage of seedlings, but is the shortage of manpower which might be encountered when planting approximately 100 million seedlings annually in the province. Labour is one of the critical problems in our present planting programs on the coast. Turn-over in the labour force is very high due to the tedious nature of the work, competition for man-power with other industries, and in some cases, seniority agreements with unions.

Planting, relatively speaking, provides optimum stocking. Artificial seeding, on the other hand, and based on ten years of experience on the coast, provides satisfactory stocking at least 75 per cent of the time, if carried out over a number of years and where ground conditions favour its success.

Considering seed, planting stock, and labour, direct costs of planting are between two and three times those of aerial seeding. From this economical aspect, and especially considering Crown lands in remote parts of the Interior, do we want optimum stocking on one unit of land, or satisfactory stocking on two units of land for the same cost?

\section{Review of Artificial Seeding on the Coast}

Research in artificial seeding has progressed for almost 30 years on the coast of B.C. A summary of seeding research was published by Garman and Orr-Ewing in 1949 (3). The conclusions of these authors were:

1. The deer-mouse is undoubtedly the greatest single obstacle to the success of direct seeding.

2. Satisfactory direct seeding of Douglas fir is out of the question until some form of cheap and practical control of this mouse has been devised.

3. There is no question that successful direct seeding with Douglas fir could be a very valuable asset to reforestation programs in this Province.

4. It should not be overlooked that, even with effective control of rodents, direct seeding will not succeed on every site. Areas will have to be carefully chosen, as it has been shown that drought in the early life of the seedling can cause heavy mortality.

5. Aerial seeding is undoubtedly the cheapest form of reforestation presently known, but has not been perfected. When the rodent problem has been solved, this method of reforestation will have very wide possibilities.

6. Aerial seeding will not always be practical, especially on smaller areas, but ground seeding costs are also subtantially below those of planting.

J. M. Finnis was engaged in direct seeding research for the B.C. Forest Service on the coast from 1950 to 1960 . His work, which centered around rodent control and seeding techniques, has shown that seeding can be applied on the coast with effective rodent control, and with a high chance of success at approximately one half the direct cost of planting. Allied work in the Pacific North-West States substantiates his findings, and at present aerial seeding plays a major role in reforestation in coastal Washington and Oregon. 
Why is seeding not used widely on the B.C. coast? The Forest Service provides companies with planting stock, and as a result, absorbs at least $\$ 4$ per acre of the real cost of planting. The resulting cost margin between planting and seeding, when related to the differential risk involved in the two operations, and the quality of the resultant stocking makes planting more attractive to private companies.

There are, however, areas of the coast, which, due to inaccessibility, are extremely costly to plant. Cost of transportation and accommodation of crews at these areas makes planting expensive. Aerial seeding, which requires a minimum of labour, and can be carried out quickly and with a minimum of organization has definite value under such conditions.

Aerial seeding has by no means been perfected on the coast. Rodents still eat many seeds; distribution of seed from helicopters requires further study, and above all evaluation of conditions favourable to successful seeding is incomplete.

\section{Review of Artificial Seeding in the Interior}

The interior districts of B.C. present an entirely different problem than is found on the coast. In 1957 the Surveys Division estimated that there were 1.6 million acres of N.S.R. which were plantable and not expected to restock naturally (1).

Lightning causes large forest fires in remote areas. In 196110.6 per cent of the forest fires in the Prince George Forest District exceeded 500 acres in size (2). An average of 770 acres was planted annually in all interior districts during the period 1952 to 1961 (2). In 1961, 1400 acres were planted, which is much less than the acreage of one large forest fire (2). Aerial seeding has wide potential for reforesting some of the large inaccessible burns. Planting in such remote areas, and with the typical short planting season of the interior, will be expensive, with anticipated costs of $\$ 30$ per acre or more. Many of the sites may not have the growth potential to merit such expenses. Aerial seeding, although it does not give optimum stocking, can be expected to satisfactorily restock a large proportion of N.S.R. in the Interior.

Research in seeding has been conducted in the Prince George, Kamloops and Nelson Forest Districts since the early 1950's. At present research officers in these districts are studying seeding in an effort to evaluate its potential. Continued research in seeding of white and Engelmann spruce is desirable. Some Critical Aspects of the Wide Application of Seeding

1. Can the seed collection program be accelerated to provide large quantities of seed?

The amount of seed required to seed one acre to Douglas fir at $1 / 2$ pound per acre will produce enough planting stock to plant 20 acres at 500 seedlings per acre. It is anticipated that approximately 50,000 pounds of seed would have to be collected during good seed years if seeding is widely used in the future.

Such a program would present major organizational difficulties.

2. Can we identify ground conditions which will limit the risk of failure, and thereby make artificial seeding an important reforestation technique?

On the coast considerable research has been conducted so that we can reasonably identify ground conditions receptive to seeding. Seedling 
establishment has been correlated with aspect, mineral soil, shade and plant cover but more research is necessary.

In the interior some information has been obtained on the conditions which are receptive to natural seeding. This information should also apply to artificial seeding. Further work is necessary.

3. Where would artificial seeding fit in a program of tree improvement? John Duffield, during an H. R. MacMillan lecture at U.B.C. in 1962, had this to say:

"No discussion of tree improvement can ignore the increasingly effective practice of direct seeding. While it seems unlikely that the relatively costly seed from grafted seed orchards will be used in the wasteful process of direct seeding, it may be practical to use seed production areas for this purpose."

For many years high cost "elite" seed will be used only on the best sites in B.C.

\section{SUMMARY}

1. Planting alone cannot reforest the existing and accumulating N.S.R. areas, particularly in the interior.

2. Both planting and seeding must be employed in future reforestation programs.

3. Aerial seeding does not require a large labour force, which is one of the major problems in planting.

4. Aerial seeding makes most efficient use of the time element.

5. Artificial seeding costs less than half the direct cost of planting.

6. Advanced planning, the high cost of transportation of stock and crews to remote areas, and the cost of crew accommodation can be greatly reduced by aerial seeding.

7. Seed collection can be expanded to provide seed.

8. Artificial seeding has a definite value in areas where planting is impossible. or uneconomical. Areas with rocky, shallow soils unsuitable for planting, or sites which do not have the productive capacity to justify planting are two important examples.

9. With our present knowledge we can use artificial seeding as an operational practice on the coast.

10. Continued research is needed in rodent control so that even more efficient use can be made of seed in the future.

11. Continued research is needed in seed dissemination and distribution from seeding devices.

12. Continued research is needed in determining the influence of site and weather on artificial seeding.

\section{Literature Cited}

1. B.C. Forest Service, 1958, Continuous Forest Inventory of British Columbia, Initial Phase, 1957. pp. 43-44. Forest Surveys and Inventory Division, Victoria, B.C.

2. B.C. Forest Service, 1962, 1961 Annual Report, Queen's Printer, Victoria, B.C.

3. GARMAN, E. H. and A. L. ORR-EWING, 1949. Direct-seeding Experiments in the Southern Coastal Region of British Columbia 1923-1949. B.C. Forest Service, Research Division. Technical Publication T.31. 